Arquivos Brasileiros de Educação Física

Brazilian Archives of Physical Education

ABEF

\title{
Os dirigentes desportivos em Portugal: Estudo sobre a modalidade de hóquei em patins
}

Sports managers in Portugal: a study on rink hockey modality

Los dirigentes deportivos en Portugal: Estudio de la modalidad de hockey sobre patines

\author{
Mário Rui Coelho Teixeira ${ }^{1}$ \\ Ricardo Rafael Soares Leão ${ }^{2}$ \\ Nuno Miguel Castanheira Almeida ${ }^{3}$
}

\section{Resumo}

Objetivo: A realização deste estudo tem como objetivo encontrar respostas sobre a formação académica dos dirigentes desportivos de Hóquei em Patins da primeira e segundas divisões, bem como outros dados interessantes que possamos recolher, afim de termos uma análise mais detalhada da classe. Esta questão é importante para que possamos perceber o estado atual da modalidade e com isso ser possível elaborar por parte das entidades competentes, um planeamento que permita melhoramentos a todos os níveis e resulte na evolução do Hóquei em Patins. Métodos: O método adotado para responder às questões da investigação consistiu num questionário online semiestruturado através da plataforma Google Forms ${ }^{\circledR}$, dividido em cinco partes: dados do inquirido, a formação e experiência do mesmo, as dificuldades no desempenho da função, os objetivos do clube e importância da formação académica. Resultados: Como principais resultados, foi possível aferir que os dirigentes desportivos do Hóquei em Patins, carecem de formação académica, não tendo deste modo competências basilares e conhecimentos para o correto desempenho da sua função. Foram encontradas diversas dificuldades, nomeadamente de ordem financeira, o que limita em parte o trabalho dos dirigentes desportivos, que na grande maioria dos casos não são profissionais. Conclusão: Como principal conclusão da investigação, destaca-se que os dirigentes desportivos consideram a formação académica como algo importante para o desempenho da sua função, no entanto, não consideram importante o suficiente para que os force a procurar atualizarem-se em relação a determinadas matérias importantes para a gestão desportiva.

Palavras - chave: Hóquei. Administração de Recursos Humanos. Organização e Administração.

\footnotetext{
Abstract

Goal: The purpose of this study is to find answers about the academic formation of the first and second division hockey leaders, as well as other interesting data that we can collect, in order to have a more detailed analysis of the class. This issue is important so that we can understand the current state of the sport and with this, it's possible to elaborate by the competent authorities a planning that allows improvements at all levels and results in the evolution of hockey. Methods: In order to answer the research questions, a semi-structured online questionnaire was developed through the Google Forms ${ }^{\circledR}$ platform, divided into five parts: interviewer data, training and experience, difficulties in the performance of the function, the objectives of the club and importance of academic training. Results: The collected data allowed us to verify that the sports directors of hockey, don't have the academic educations and do not have basic skills and knowledge for the correct

1. Professor e Investigador, Diretor do Mestrado em Direção e Gestão Desportiva; Departamento de Desporto e Saúde, Universidade de Évora - Portugal; mario.teixeira@uevora.pt ; 2. Departamento de Desporto e Saúde, Universidade de Évora - Portugal; kado.sintra@hotmail.com ; 3. CíTUR, ESTM, Politécnico de Leiria, Portugal; nunoalmeida@ipleiria.pt ; Autor para correspondência: Mário Rui Coelho Teixeira, Universidade de Évora - Escola de Ciências e Tecnologia, Departamento de Desporto e Saúde, Colégio Luís António Verny, Rua Romão Ramalho, nº 59, 7000-671, Évora - Portugal.
} 
performance of their function. A number of difficulties have been found, mainly in financial terms, which in part limits the work of sports managers, who in the vast majority of cases are not professionals. Conclusion: Although these data are found, sports managers consider academic education as important for the performance of their job, but do not consider it important enough that it forces them to search for new skills.

Keywords: Roller Hockey; Human Resource Management; Organization and Administration.

\section{Resumen}

Metas: El propósito de este estudio es encontrar respuestas sobre la formación académica de los líderes de hockey de primera y segunda división, así como otros datos interesantes que podemos recopilar, para tener un análisis más detallado de la clase. Este problema es importante para que podamos entender el estado actual del deporte y, con esto, es posible elaborar por las autoridades competentes una planificación que permita mejoras en todos los niveles y resulte en la evolución del hockey. Metodos: Para responder a las preguntas de investigación, se desarrolló un cuestionario en línea semiestructurado a través de la plataforma Google Forms ${ }^{\circledR}$, dividido en cinco partes: datos del entrevistador, capacitación y experiencia, dificultades en el desempeño de la función, objetivos del club e importancia. de formación académica. Resultados: Los datos recopilados nos permitieron verificar que los directores deportivos de hockey, no tienen la educación académica y no tienen habilidades y conocimientos básicos para el desempeño correcto de su función. Conclusión: Se han encontrado varias dificultades, principalmente en términos financieros, que limitan en parte el trabajo de los gerentes de deportes, que en la gran mayoría de los casos no son profesionales. Aunque se encuentran estos datos, los gerentes deportivos consideran que la educación académica es importante para el desempeño de su trabajo, pero no lo consideran lo suficientemente importante como para obligarlos a buscar nuevas habilidades.

Palabras clave: Hockey Sobre Patines; Gestión de Recursos Humanos; Organización y Administración.

\section{INTRODUÇÃO}

A atividade de Dirigente

Desportivo começa a passar por

múltiplas dificuldades face às alterações sociais no desporto atual. Ao mesmo tempo, os apoios por parte do Estado para com estas organizações desportivas sem fins lucrativos começam a ser cada vez mais escassos. Como em outras valências do marketing, o marketing desportivo procura atender às necessidades e desejos dos consumidores. Desta forma, o marketing pode contribuir para uma oferta de serviços desportivos e produtos relacionados com o desporto para os consumidores ${ }^{1}$.

É um fato que os clubes desportivos de hoje em dia se distanciaram, em muitos casos, do objetivo que motivou a sua fundação promover a prática desportiva. Atualmente o objetivo de muitos clubes, face à realidade social vivida, está muito dado a valorizar em excesso a vitória, esquecendo regularmente, o valor social 
e cultural do desporto. Se atualmente existe a necessidade de analisar a particularidade do desporto profissional e da atividade empresarial a ele associada, também é necessário procurar a renovação/atualização dos meios de gestão utilizados pelos clubes e pelas associações, pois estas organizações desportivas necessitam de um tipo de gestão que lhes permita preparar o futuro ${ }^{2}$.

Há então necessidade de inovar e renovar os agentes desportivos tendo em vista o desafio da qualidade e de ofertas diferenciadas que cada vez mais estão presentes na sociedade atual e não por aquilo que existiu no passado. Há que suscitar nos agentes desportivos uma tomada de consciência acerca da necessidade de formação pelas mudanças em curso no desporto e na vida $^{3}$. Nesse sentido, com este trabalho pretendemos obter resultados que nos permitam verificar por que razão o desporto que mais títulos coletivos dá a Portugal, tem tanta dificuldade em afirmar-se na sociedade como uma das principais modalidades. Portugal tem, senão o melhor campeonato, um dos melhores campeonatos do mundo, algo que permite que o produto seja muito vendável, pois muitos dos melhores jogadores do mundo competem em Portugal o que permite ter competitividade e espetacularidade nos jogos, algo que o público procura, especialmente num país em que o Hóquei em Patins tem bastante tradição. Mas por diversas razões, entre as quais pode estar a qualidade dos dirigentes e a sua capacidade para promover e "profissionalizar" a modalidade, questiona-se porque tarda o Hóquei em Patins em afirmar-se como uma das principais modalidades no País. Constatando-se por vezes que algumas decisões tomadas pelos próprios dirigentes não são abonatórias em prol da modalidade.

Esta investigação permite o acesso à informação necessária para perceber as características comuns sobre os principais agentes responsáveis pela gestão das organizações de Hóquei em Patins, definindo se a sua formação é a ideal para o cargo que desempenham na atividade de Dirigente Desportivo.

\section{MÉTODOS}

Os dados foram obtidos através de um questionário online semiestruturado através da plataforma Google Forms®, dividido em cinco partes: na primeira parte encontramos alguns dados do inquirido, na segunda 
procuramos conhecer a sua formação e experiência, na terceira parte saber quais as dificuldades no desempenho da função, na quarta, quais eram os objetivos do clube e por fim, na quinta parte, a importância da formação académica. Os questionários foram preferencialmente respondidos por agentes com funções importantes dentro das organizações, nomeadamente, os presidentes, os vice-presidentes e os diretores, sendo todos os questionários respondidos via online.

Os dados foram tratados com recurso a ferramentas de cálculo automatizado por forma a permitir uma análise mais percetível das informações constantes nos questionários. Os dados foram recolhidos após o final da época 2016/2017, pelo autor deste estudo, entre os meses de julho e outubro de 2017, tendo os questionários sido enviados para os clubes via e-mail numa primeira e segunda instância. Devido a alguma dificuldade de obtenção de respostas, procurou-se numa terceira fase, para além de novo envio de e-mails para as entidades e ainda entrando-se em contacto com pessoas ligadas aos clubes em falta. Ao todo foram enviados cerca de 50 inquéritos - tendo sido posteriormente enviada uma recordatória solicitando a colaboração na submissão de respostas.

Os dados recolhidos através dos questionários foram maioritariamente analisados com recursos a ferramentas de automatização, permitindo, desta forma, retirar conclusões dos mesmos, os quais se basearam na utilização do Microsoft Excel para serem recolhidos. Numa das análises em específico foi utilizada a média, moda e mediana. Dada a proximidade como praticante federado, decidiu-se abordar especificamente apenas a modalidade de Hóquei em Patins, procurando elaborar o Perfil de Dirigente Desportivo colocando questões como: "Qual o seu cargo? Qual a sua idade? Foi ex-praticante? Tem experiência anterior como gestor desportivo? É profissional da sua função? Qual a sua formação académica? Quais as maiores dificuldades sentidas no desempenho da sua função? Qual a importância da formação académica de um dirigente?”

\section{RESULTADOS}

Ao analisarmos os dados, foi possível constatar a falta de formação adequada para o cargo é algo que em nada beneficia a modalidade e o seu crescimento. Corroborando o que já 
havia sido defendido antes ${ }^{4}$, onde os processos contemporâneos de mudança exigem uma formação mais específica dos dirigentes desportivos. No entanto só foram possíveis obter 19 respostas, correspondendo a uma taxa de respostas de $38 \%$.

É preocupante que apenas um dos entrevistados tenha formação na área de Gestão Desportiva e isto não implica que a gestão feita por parte dos outros dirigentes seja negativa, mas implica que não tenham tantas bases e não estejam tão bem preparados para conseguir obter um rendimento ideal da Instituição, pois para a sua gestão, são necessários muitos conhecimentos em diversas áreas que farão falta para existir uma otimização da mesma. É importante também notar o interesse e a disponibilidade que existe para melhorar a classe diretiva no Hóquei em Patins. Dos 16 inquiridos que não têm qualquer tipo de formação, apenas 4 têm interesse em adquirir conhecimentos que lhes permitam melhorar o seu desempenho e da sua Instituição, o que representa apenas um quarto da amostra, aparentemente, apesar de a situação atual não ser a mais correta, também não existe grande interesse por parte dos dirigentes em melhorá-la, sejam quais forem as suas razões.

Foi ainda possível aferir através de outra questão, que numa escala de 0 a 5 , em que 0 é péssimo e 5 é excelente, nenhum dos dirigentes avalia a sua prestação de forma negativa e que apenas 3 deles se avaliam de forma mediana. Todos os restantes, ou seja, 16 inquiridos, avaliam o seu desempenho de uma forma bastante positiva (4 e 5), o que nos leva a pensar que ou a formação não é de todo importante, pois avaliam o seu desempenho de forma positiva demonstrando que as dificuldades encontradas na gestão da instituição não são suficientes para obter um mau desempenho, ou então mesmo sem essa formação o Hóquei em Patins não exige um conhecimento e uma capacidade de gestão rigorosa e profissional que não sejam capazes de a contornar sem formação.

Perante esta análise, podemos concluir que o Hóquei em Patins carece de pessoas formadas academicamente ou não, na área da gestão desportiva, a fim de permitir que haja uma maior capacidade e um maior conhecimento das diversas áreas intervenientes na gestão desportiva, que muitos indivíduos pensam não ser relevante e com isso 
levam a que a modalidade seja gerida de uma forma leviana e pouco profissional não contribuindo para $\mathrm{o}$ seu crescimento.

\section{DISCUSSÃO}

O Hóquei em Patins atual tem sofrido algumas críticas quanto à sua forma de gestão e quanto ao rumo que está a levar, questionando-se o porquê de com tantos recursos disponíveis ao nível do espetáculo proporcionado, não se conseguir impulsionar o hóquei para um patamar desejado. É possível inferir que, para isso acontecer é necessário que o trabalho de base, ou seja, nos clubes, também seja melhor, mais estrutural e mais organizado, de forma a permitir uma melhor orientação da modalidade. No entanto, se cabe aos clubes fazerem esse trabalho de base, também é necessário a Federação dar o exemplo, tomando medidas que permitam que tal aconteça de maneira a haver uma conjugação de ideias e um planeamento que todos possamos seguir a fim de melhorarmos a modalidade.

Atualmente, os dirigentes desportivos têm que entender que apesar de na sua grande maioria não serem profissionais, a sua função não se pode basear em apenas colocar, e manter em funcionamento, um certo número de secções desportivas. Apesar de todas as dificuldades, nomeadamente de ordem financeira, devem ter brio em desempenhar corretamente os seus cargos, quanto mais não seja, a fim de serem reconhecidos pela população que frequenta as suas instituições possibilitando-lhes melhores condições de prática desportiva. Para isso os dirigentes desportivos, devem estar munidos de um conjunto de competências específicas que os tornem capazes de elaborar um plano de ação, que permita ir ao encontro da missão e dos interesses da própria Instituição. Devem ser capazes de monitorizar o desempenho da sua estrutura avaliando os resultados alcançados, de modo a poder estruturar novos projetos de ação sobre bases sólidas e sustentáveis.

Apesar das conclusões retiradas, este estudo apresentou algumas limitações, como a dificuldade em encontrar os contactos eletrônicos da população total que desejávamos inquirir, o qual só foi possível através de um contacto pessoal num clube que nos disponibilizou esses mesmo e-mails, a fim de procedermos à realização do inquérito. Outra dificuldade, prendeu-se pelo facto de menos de 50\% dos inquiridos ter respondido ao inquérito, o 
que não nos permite analisar com um maior grau de exatidão o problema do estudo, no entanto pensamos que os inquéritos recolhidos são suficientes para analisar o estado em que a modalidade se encontra.

Apesar de haver alguns estudos de Hóquei em Patins ${ }^{5,6}$, estes são apenas baseados nos aspetos técnicos, táticos $\mathrm{e}$ de análise individual e coletiva dos atletas, sendo que outra das limitações encontradas deve-se ao fato de não haver estudos que englobem a gestão desportiva e o Hóquei em Patins, não nos possibilitando assim efetuar uma comparação com estudos anteriores. Seria interessante que fossem elaborados estudos idênticos de forma a ter um termo de comparação que nos permita compreender qual a evolução da classe diretiva do Hóquei em Patins de forma e a elaborar planos formativos específicos para que possamos melhorar o estado da modalidade fora de pista.

Ainda na área acadêmica, seria interessante conseguir um maior número de respostas a nível Nacional em estudos futuros pois, após uma recolha mais completa da realidade diretiva do Hóquei em Patins Português, poderíamos futuramente estudar e comparar com a realidade Espanhola, sendo interessante verificar as diferenças entre os dois países mais dominantes da modalidade. Seria também interessante, perceber se as competências identificadas aos dirigentes, têm ou não correlação com o seu desempenho em diversas áreas, como económico/financeira, captação de recursos humanos, infraestruturas, entre outras. Outra recomendação é estudar se os diferentes cargos inquiridos apresentam diferentes dificuldades no desempenho das suas funções, pois o presidente pode não ter as mesmas dificuldades que o vice-presidente.

É necessário realizar algumas recomendações à Federação de Hóquei em Patins, às Associações e aos Clubes. Perante as conclusões do estudo foi possível verificar que a classe diretiva do Hóquei em Patins não está devidamente preparada para responder corretamente à grande parte das exigências diárias da atividade. Seria interessante por parte da Federação de Hóquei em Patins e das Associações promoverem ações formativas no sentido de dotarem os dirigentes desportivos de mais ferramentas que sejam benéficas no seu trabalho diário. Todas e quaisquer ações no sentido de melhorar a modalidade serão bem-vindas e só contribuem para 
uma evolução da mesma. Não pode ser pedido aos clubes que respondam estruturalmente e organizativamente de forma quase profissional, quando a maioria deles não tem bases nem pessoas capacitadas para o fazer e nesse sentido estas ações formativas seriam importantes para que os dirigentes possam entender como gerir de forma mais indicada as suas organizações e assim promoverem o seu melhor funcionamento bem como uma consequente evolução da modalidade.

\section{CONCLUSÃO}

Após a análise dos dados, podemos concluir que apesar de todo o empenho e dedicação que possa existir por parte dos dirigentes desportivos, são evidenciadas carências na sua formação acadêmica, sendo que a maioria não foi praticante desta mesma modalidade, o que não sendo um fator limitativo para o bom desempenho do cargo, aliado à falta de formação, em nada contribui para o bom desempenho da função. A todos estes fatores, podemos ainda juntar o fato de mais de metade dos dirigentes não ter qualquer experiência anterior como gestor desportivo. As competências dos dirigentes desportivos devem dar resposta às exigências atuais, pois a sociedade está em constante evolução e as pessoas procuram constantemente novas e melhores formas de melhorarem o seu estilo de vida.

Notou-se também que a faixa etária dos dirigentes inquiridos não está muito envelhecida, no entanto, seja qual for a idade do dirigente, é muito importante ter uma visão global sobre os problemas, encarando-os como algo natural e que deve ser devidamente acautelado e planejado, possibilitando a sua rigorosa resolução. No entanto, para que isso aconteça é necessário que os dirigentes desportivos estejam mentalizados para as dificuldades pessoais e profissionais que enfrentam, preparando-se de uma forma mais cuidada, algo que não acontece atualmente. Por fim e infelizmente para a modalidade, podemos concluir que serão necessárias grandes alterações a nível dos responsáveis e com isto não quer dizer que os atuais responsáveis sejam incompetentes, no entanto pensamos ser necessário, que se atualizem de forma a melhorarem os seus conhecimentos e proporcionarem ao Hóquei em Patins uma evolução correta e organizada, que permita à modalidade atingir patamares que todos desejamos. 


\section{REFERÊNCIAS:}

1. Hoye, R., Smith, A., Nicholson, M., Stewart, B. (2018). Sport Management Principles and Applications. Fifth Edition. Routledge. New York

2. Correia, A. (2000)). Estratégias das Federações Desportivas - Estudo das principais federações portuguesas do ciclo olímpico de 1993 a 1996. Lisboa, Edição Centro de Estudos e Formação Desportiva.

3. Bento, J. (1998): Desporto e Humanismo - o campo do possível. Ed. Uerj, Rio de Janeiro.

4. Fahlén, J., Stenling, S. (2018). (Re)conceptualizing institutional change in sport management contexts: the unintended consequences of sport organizations' everyday organizational life, European Sport Management Quarterly, ISSN: 1618-4742.

5. Gallén, C. (1991). Evolución histórica del Hockey sobre Patines. Apunts: Educació Física i Esports, 23, pp. 77-85.

6. Gayo, A. (1992). El componente táctico-estratégico en Hockey sobre Patines - Aproximación conceptual. Cadernos técnico-pedagógicos do INEF - Galicia, La Coruña.
Informações do artigo / Information of this article:

Recebido: 20/04/2019

Aprovado: 02/05/2019

Publicado: 05/10/2019

Received: 20/04/2019

Approved: 02/05/2019

Published: 05/10/2019

Mário Rui Coelho Teixeira

ORCID: 0000-0002-0822-2623

\section{Agradecimentos}

Um agradecimento a todos os clubes e associações que se disponibilizaram a responder ao inquérito pedido, dando um importante contributo, pois sem eles não seria possível a realização do presente estudo.

\section{Conflito de interesses}

Os autores declaram não haver conflito de interesses.

Como citar este artigo:

Teixeira, M. R. C.; Leão, R. R. S.; Almeida, N. M. C. Os dirigentes desportivos em Portugal: Estudo sobre a modalidade de hóquei em patins. Arq. Bras. Ed. Fís., Tocantinópolis, v. 2, n. 1, Jan.Jul., p. 40 - 49, 2019. 


\section{Tabelas e/ou Figuras}

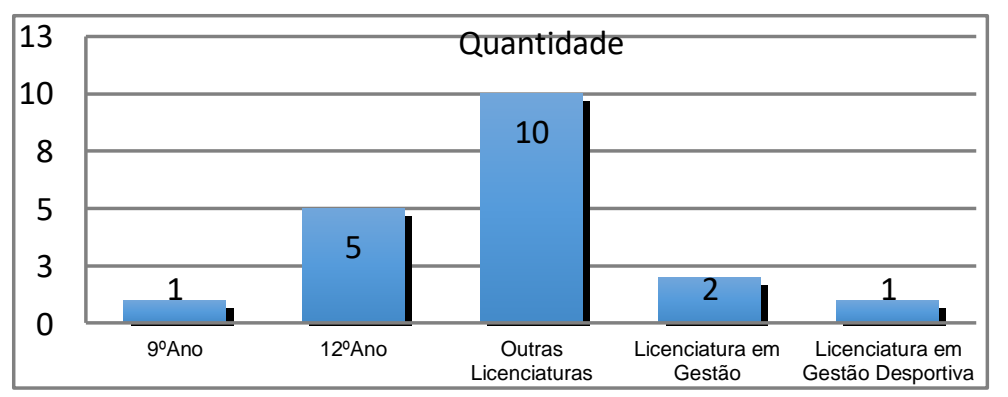

Gráfico 1 - Qual a formação acadêmica dos dirigentes desportivos. Fonte: Própria.

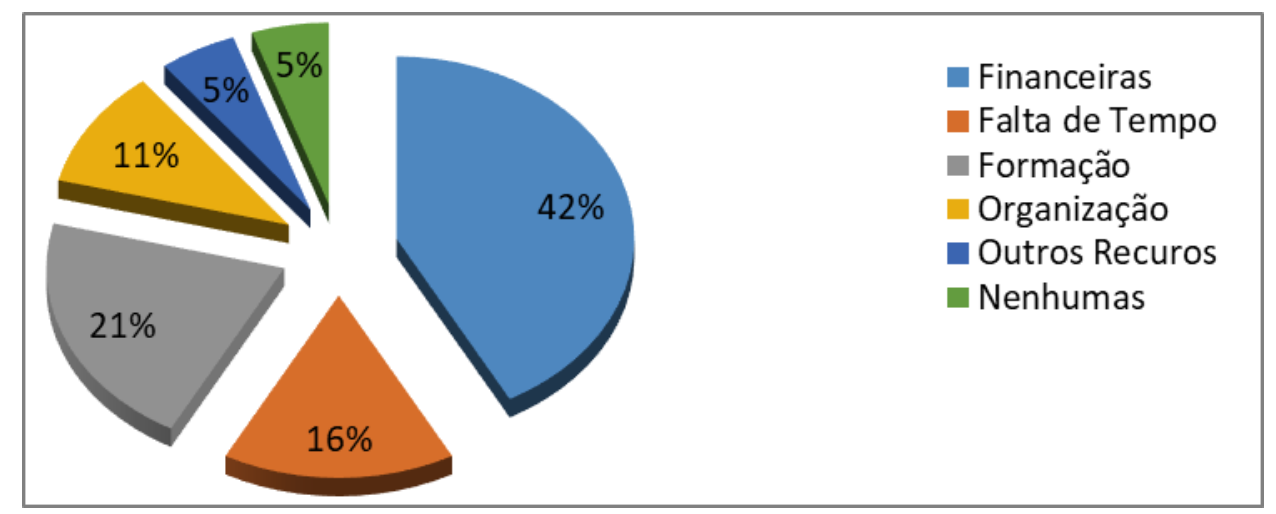

Gráfico 2 - Quais as maiores dificuldades sentidas no desempenho da sua função. Fonte: Própria.

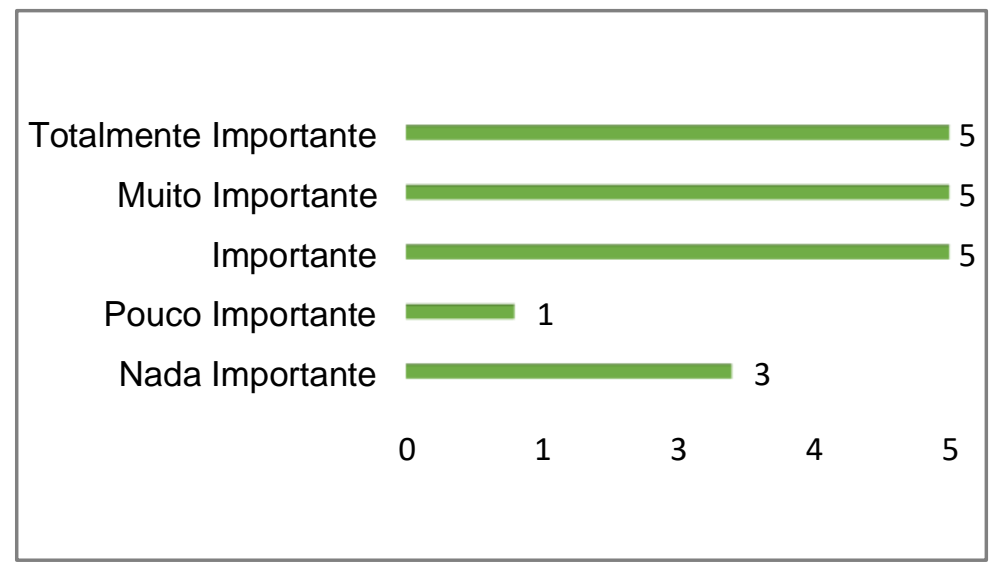

Gráfico 3 - Importância atribuída à correta formação académica de um dirigente desportivo. Fonte: Própria 